\title{
Introduction of Diagnostic Problem-Solving Approach within Undergraduate Design Courses - Application to Building Illumination
}

\section{Dr. Ahmed Cherif Megri, North Carolina A\&T State University}

Dr. Ahmed Cherif Megri, Associate Professor of Architectural Engineering (AE). He teaches capstone, lighting, electrical, HVAC and energy design courses. He is the ABET Coordinator for the AE Program. His research areas include airflow modeling, zonal modeling, energy modeling, and artificial intelligence modeling using the support vector machine learning approach. Dr. Megri holds a PhD degree from INSA at Lyon (France) in the area of Thermal Engineering and a "Habilitation" (HDR) degree from Pierre and Marie Curie University - Paris VI, Sorbonne Universities (2011) in the area of Engineering Sciences. Prior to his actual position, he was an Associate Professor at University of Wyoming (UW) and prior to that he was an Assistant Professor and the Director of the AE Program at Illinois Institute of Technology (IIT). He participated significantly to the development of the current architectural engineering undergraduate and master's programs at IIT. During his stay at IIT, he taught thermal and fluids engineering (thermodynamics, heat transfer, and fluid mechanics), building sciences, physical performance of buildings, building enclosure, as well as design courses, such as HVAC, energy, plumbing, fire protection and lighting. Also, he supervises many courses in the frame of interprofessional projects (IPRO) program. Dr. Megri wrote over 100 journal and conference papers. Overall, Dr. Megri taught more than 30 different courses at University level in the AE area.

Areas of Interests: - Zonal modeling approach, - Integration zonal models/building energy simulation models, - Zero Net Energy (ZNE) building, - Airflow in Multizone Buildings \& Smoke Control, - Thermal Comfort \& Indoor Air Quality, - Predictive modeling and forecasting: Support Vector Machine (SVM) tools, - Energy, HVAC, Plumbing \& Fire Protection Systems Design, - Computational Fluid Dynamic (CFD) Application in Building, - BIM \& REVIT: application to HVAC and Electrical/Lighting Design systems. 


\title{
Introduction of Diagnostic Problem-Solving Approach within Undergraduate Design Courses - Application to Building Illumination
}

\begin{abstract}
:
The engineers are usually confronted to two types of problems: design or investigative problems. The new design problem concerns the creation of a new product (in our case the product is a building, building component, mechanical or electrical system) and the investigative consists of fixing an existing product using a sequential diagnostic.

It is a logical, systematic search for the source of a problem so that it can be solved, and so the product or process can be made operational again. Investigation is needed to develop and maintain complex systems where the symptoms of a problem can have many possible causes.

In this paper, we introduce how these two notions have been introduced to undergraduate students through basic design courses. A case study from building engineering is presented: building illumination investigation in elementary schools will be presented and discussed.

We discuss the design work from students' point of view, and the experience earned in design, experimentation, and also in written and oral communication skills. Future plans to evaluate the effectiveness of the case studies in terms of learning outcomes, as well as plans to evaluate it in undergraduate architectural engineering training are also presented.
\end{abstract}

\section{Introduction:}

Teaching a design course is challenging and differentiates from fundamental courses at different level. The fundamental courses are based on specific laws (first law of thermodynamics, heat transfer equation, radiosity technique, and so on). The textbooks usually include a large number of examples for each topic, where students use as a reference to solve their home works and exams, through memorization, understanding and application. Design courses need more analysis and evaluation, since the problems are open-ended and usually the step-by-step process is not clearly identified in the textbooks and lectures. As well, the textbooks are not numerous and the examples within the textbooks are not abundant. Usually, undergraduate students who take design course for the first time have the tendency to focus on details and miss the big picture and the understanding of the objectives of the design problem.

It is important to explain to undergraduate students the difference between design work and diagnostic work, where the design concerns a new product that need to be produced, respecting certain rules, standards and codes. The codes and standards are there to make such product sustainable, safe, economic and respecting the environment.

The diagnostic in the other hand focuses more on the understanding of an existing product or a situation and try to correct the malfunctioning of the whole system or only a part of it. In this case, the product is already there and our job is to identify the problem (s) and come up with the appropriate solution (s), through auditing, testing and even commissioning. To do so, we need to use tools and equipment to measure and identify the parameters that help us to identify the problem (s). This kind of work needs different expertise and understanding of how to measure and identify the fundamental parameters, such as temperature, pressure, concentration, illuminance, amperage, voltage, airflow, and energy consumption. 
Design and troubleshooting are considered as two subcategories of problem solving (McCade). Problem solving has been defined in many ways. Ritz describes a problem as a need which must be met (Ritz, et al. 1986a). The main difference between the two subcategories is the fact that the design is a "proactive" problem solving (Baker \& Dugger, 1986) and the troubleshooting is a "reactive" problem solving (Baker $\&$ Dugger, 1986). The design involves more innovation, where the troubleshooting involves the recognition that technology encompasses (Baker \& Dugger, 1986).

More recently, Design is defined by Nielsen (2003), "A Problem is basically impression of a tension or a contrast between two conditions: Condition of Desires and Actual Condition". The successful design of an item transforms a condition of "Desire" (or need) into one of "Actuality". These definitions are supported by Jonassen (2004) when he writes "First, a problem is an unknown entity in some context", and "Second, finding or solving for the unknown must have some social, cultural or intellectual value". He then adds one vital ingredient, "someone believes that it is worth finding the unknown". Jonassen (2004) in his book has focused on the following three types of problems: story problems, troubleshooting problems, and case and system and policy analysis problems.

A problem-solving method describes a reasoning process that efficiently achieves a goal by applying domain knowledge. Nickols (2012) states that choosing the right problem solving approach makes a difference. He identifies three different problem solving tasks: repair, improve, and engineer. Stojcevski (2005) mentions that problem solving is a special kind of skill to learn. Benjamins et al. (1995), states that a problem-solving method cannot directly be applied because of the existence of a gap between, on the one hand, a problem-solving method and the domain knowledge it uses, and, on the other hand, a problem-solving method and the goal that it is supposed to achieve. He distinguished two types of assumptions that are able to bridge the gap: one type of assumption is used to strengthen a problemsolving method, and the other to weaken the goal to be achieved.

In this paper, we introduce how these two concepts have been introduced to undergraduate students within engineering design courses. A case study from building engineering is presented: building illumination of elementary schools. The methodology employed will be demonstrated step-by-step and the results are presented and discussed.

We discuss the design program from students' point of view, and the experience earned in design, experimentation, and also in written and oral communication skills. Future plans to evaluate the effectiveness of the case studies in terms of learning outcomes, as well as plans to evaluate it in undergraduate architectural engineering training are also presented.

\section{Illumination Building Design:}

The design concerns the creation of a new product (in our case the product is a building or one of its components, mechanical or electrical system). For safety and economic reasons, the designer needs to take into account the requirements of multiple standards and codes, such as the International Code Council (ICC) codes, Illuminating Engineering Society (IES) standards, National Electrical Code (NEC) code, and American Society of Heating and Refrigeration Engineers (ASHRAE) standards. Among ASHRAE standards, the designer needs to satisfy ASHRAE 55-2010, ASHRAE 62-2010, and ASHRAE 90.1-2013. The designer needs to satisfy what applicable of the fifteen ICC codes, such as Building Code, Energy Conservation Code, Fire Code, Plumbing Code, and Zoning Code.

In the case of building illumination, the design process start with gathering data related to the building and rooms dimensions (length, width and height), the considered color of the walls, ceiling, and floor. 
The height of the fixtures (for recessed fixture, the height is zero). The IES recommended light levels (Table 1). The estimation of the number of fixtures and their locations is then calculated.

Table 1: IES illuminance recommendations (recommended light levels)

\begin{tabular}{|c|c|}
\hline Task Area & Illuminance (fc) \\
\hline Corridors/Stairways/Restrooms & $10-20$ \\
Storage Rooms & $10-50$ \\
Conference Rooms & $20-50$ \\
General Offices & $50-100$ \\
Drafting/Accounting & $100-200$ \\
Areas with VDTs & 75 \\
Classrooms & $50-75$ \\
Cafeterias & 50 \\
Gymnasiums & $30-50$ \\
Merchandising & $30-150$ \\
Manufacturing Assembly & $50-500$ \\
Parking Areas (uncovered) & $1-2$ \\
\hline
\end{tabular}

In the design process, the number of fixtures is estimated based on IES requirements, work area, coefficient of utilization (CU), the amount of light produced by each lamp (lumens) and many other coefficients, such as:

- LOF: lamp operating factor (a multiplier to modify the lumens output of each lamp under filed conditions).

- LLD: lamp lumen depreciation

- LDD: luminaire dirt depreciation

$L O F=V F * T F * B F * P F$

- VF: voltage factor

- TF: temperature factor

- BF: Ballast factor

- PF: position tilt factor (for HID lamps only)

The accurate estimation of these coefficients is essential for an accurate estimation. This depends on many factors, like understanding the type of lamps/luminaires used (operation factor, lumen depreciation, ballast factor) the type of maintenance, the type of environment designed (dirt depreciation).

The design includes quantitative and qualitative decisions, such the decision about the color temperature (CT), and color rendering (CRI). As well the design process includes the selection of the type of fixture that need to be used, economic analysis and the comparison between different solutions to select the most suitable for the appropriate design case.

\section{Problem-solving Approach:}

The diagnostic consists of fixing an existing product using a sequential procedure. It is a logical, systematic search for the source of a problem so that it can be solved, and so the product or process can be 
made operational again. Diagnostic is needed to develop and maintain complex systems where the symptoms of a problem can have many possible causes.

The objective of this project is to compare the IES requirement for classrooms to the actual classrooms illumination in elementary schools in Greensboro, NC. In this project, we will take measurements from three elementary schools located in Greensboro, compare them to a simulated average of the classrooms using the program Visual 2012, and then compare both values to the IES requirement for classrooms.

The IES illumination requirement at the level of the desktops (the amount of light that should reach the desktops) of classrooms is 50-75 foot-candles (fc). Since the standard does not differentiate between the amounts of light that need to reach the desks for elementary schools compared to high schools and college classrooms, we will take the mean of the IES standard, and average it with the base number. This should account for the difference in height between the desks in elementary schools to all others. The average considered is $62 \mathrm{fc}$. Any number considered between $50 \mathrm{fc}$ and $75 \mathrm{fc}$ is acceptable. The hypothesis for this project is that the schools as well as the simulated classrooms will all comply with the IES standards.

The procedure for the experiment is to first take the dimensions of the room (length, width, and height) to calculate the area, and cavity ratios. The wall color, floor color, and floor type are also recorded. The next step is to then estimate the ceiling, floor, and room cavity ratios for each classroom. The information regarding the lamps and fixtures used in the room need to be found. In particular, the type and amount of fixtures, the number, type and characteristics of the lamps used in the fixtures are needed. Once all of these basic observations about the room are found, then the measuring of the foot-candles on the work plane may begin. The illuminance in each room was measured in five different locations throughout the work plane under four different conditions. These conditions were the blinds drawn and lights on, blinds shut and lights on, blinds drawn and lights off, and blinds shut and lights off. Tables 2 to 5 show the measurement of illuminance conducted in three schools. The figures 1 to 5 show the comparison of the level of lights in the three schools.

Table 2: Sample of the measurements (Blinds Up, Lights On)

\begin{tabular}{|c|c|c|c|c|c|c|c|}
\hline & & \multicolumn{6}{|c|}{ Blinds Up, Lights On } \\
\hline & & FC 1 & FC 2 & FC 3 & FC 4 & FC 5 & Avg FC \\
\hline \multirow[t]{6}{*}{ School 1} & Room 1 & 53.2 & 86.2 & 51.8 & 95.4 & 87.1 & 74.74 \\
\hline & Room 2 & 37.6 & 68.6 & 59.6 & 54.3 & 37.8 & 51.58 \\
\hline & Room 3 & 32.4 & 65.4 & 73.2 & 70.3 & 53.4 & 58.94 \\
\hline & Room 4 & 57 & 68.2 & 71.7 & 76.8 & 61.2 & 66.98 \\
\hline & Room 5 & 79.7 & 80.2 & 71.2 & 67.9 & 90.8 & 77.96 \\
\hline & Room Avg & 51.98 & 73.72 & 65.5 & 72.94 & 66.06 & 66.04 \\
\hline \multirow[t]{6}{*}{ School 2} & Room 1 & 52.1 & 48.8 & 45.4 & 49 & 38.3 & 46.72 \\
\hline & Room 2 & 49.1 & 42.1 & 48.8 & 33.1 & 26.8 & 39.98 \\
\hline & Room 3 & 46.9 & 48.9 & 51.4 & 50.4 & 39.6 & 47.44 \\
\hline & Room 4 & 42 & 47.1 & 43.1 & 49.4 & 22.3 & 40.78 \\
\hline & Room 5 & 33 & 40.8 & 47.4 & 30.4 & 21.2 & 34.56 \\
\hline & Room Avg & 44.62 & 45.54 & 47.22 & 42.46 & 29.64 & 41.896 \\
\hline \multirow[t]{6}{*}{ School 3} & Room 1 & 51 & 64.2 & 80 & 73.6 & 62.3 & 66.22 \\
\hline & Room 2 & 33.5 & 76.4 & 40.4 & 59.1 & 67.6 & 55.4 \\
\hline & Room 3 & 42.7 & 52.8 & 58.1 & 43 & 59.4 & 51.2 \\
\hline & Room 4 & 60.1 & 80.9 & 57.6 & 73.4 & 62.4 & 66.88 \\
\hline & Room 5 & 55.8 & 45.6 & 60.3 & 45.9 & 56 & 52.72 \\
\hline & Room Avg & 48.62 & 63.98 & 59.28 & 59 & 61.54 & 58.484 \\
\hline
\end{tabular}


Table 3: Sample of the measurements (Blinds Up, Lights Off)

\begin{tabular}{|c|c|c|c|c|c|c|c|}
\hline & & \multicolumn{6}{|c|}{ Blinds Up, Lights Off } \\
\hline & & FC 1 & FC 2 & FC 3 & FC 4 & FC 5 & Avg FC \\
\hline \multirow[t]{6}{*}{ School 1} & Room 1 & 4.7 & 1.3 & 1.2 & 0.3 & 0.3 & 1.56 \\
\hline & Room 2 & 2.1 & 2.1 & 0.7 & 0.8 & 0.4 & 1.22 \\
\hline & Room 3 & 0.2 & 0.3 & 0.3 & 1.2 & 0.8 & 0.56 \\
\hline & Room 4 & 0.2 & 0.2 & 0.1 & 0.2 & 0.1 & 0.16 \\
\hline & Room 5 & 0.2 & 0.2 & 0.1 & 0.1 & 0.1 & 0.14 \\
\hline & Room Avg & 1.48 & 0.82 & 0.48 & 0.52 & 0.34 & 0.728 \\
\hline \multirow[t]{6}{*}{ School 2} & Room 1 & 0.5 & 0.4 & 1 & 0.8 & 2.5 & 1.04 \\
\hline & Room 2 & 3 & 1 & 0.9 & 0.5 & 3.7 & 1.82 \\
\hline & Room 3 & 1.7 & 2.5 & 2.3 & 2.6 & 3.7 & 2.56 \\
\hline & Room 4 & 1.6 & 2 & 3.3 & 2.9 & 9.6 & 3.88 \\
\hline & Room 5 & 4.8 & 3.6 & 4.2 & 1.2 & 0.4 & 2.84 \\
\hline & Room Avg & 2.32 & 1.9 & 2.34 & 1.6 & 3.98 & 2.428 \\
\hline \multirow[t]{6}{*}{ School 3} & Room 1 & 3.2 & 2.3 & 1.1 & 1.7 & 2.2 & 2.1 \\
\hline & Room 2 & 0.3 & 0.3 & 0.2 & 0.3 & 0.2 & 0.26 \\
\hline & Room 3 & 2 & 1.5 & 2.7 & 0.9 & 0.7 & 1.56 \\
\hline & Room 4 & 0.6 & 0.8 & 0.9 & 0.5 & 0.6 & 0.68 \\
\hline & Room 5 & 2.1 & 3.2 & 1.6 & 0.9 & 3 & 2.16 \\
\hline & Room Avg & 1.64 & 1.62 & 1.3 & 0.86 & 1.34 & 1.352 \\
\hline
\end{tabular}

Table 4: Sample of the measurements (Blinds Down, Lights On)

\begin{tabular}{|l|l|r|r|r|r|r|r|r|}
\hline & & \multicolumn{7}{|c|}{ Blinds Down, Lights On } \\
\hline School 1 & & Room 1 & 49.4 & 60.4 & 77.2 & 86.7 & 81.5 & 71.04 \\
\hline & Room 2 & 43.6 & 71 & 63.9 & 84.5 & 34.1 & 59.42 \\
\hline & Room 3 & 41.6 & 66.2 & 71.7 & 76.8 & 61.2 & 63.5 \\
\hline & Room 4 & 62.2 & 65.4 & 62.6 & 58.8 & 52.3 & 60.26 \\
\hline & Room 5 & 78.8 & 75.9 & 70.6 & 66.7 & 89.3 & 76.26 \\
\hline & Room Avg & 55.12 & 67.78 & 69.2 & 74.7 & 63.68 & 66.096 \\
\hline School 2 & Room 1 & 52.3 & 49 & 42.8 & 48.3 & 38 & 46.08 \\
\hline & Room 2 & 45.7 & 40.8 & 48.5 & 31.7 & 23.4 & 38.02 \\
\hline & Room 3 & 46.8 & 47.1 & 51.2 & 49.8 & 36.9 & 46.36 \\
\hline & Room 4 & 42.1 & 48.5 & 40.8 & 47.3 & 23.4 & 40.42 \\
\hline & Room 5 & 28.7 & 43.4 & 41.5 & 23.1 & 17.7 & 30.88 \\
\hline & Room Avg & 43.12 & 45.76 & 44.96 & 40.04 & 27.88 & 40.352 \\
\hline School 3 & Room 1 & 47.4 & 53.2 & 48.8 & 50.1 & 55.7 & 51.04 \\
\hline & Room 2 & 60.4 & 48 & 51.8 & 50.5 & 49.9 & 52.12 \\
\hline & Room 3 & 53.3 & 58.6 & 40.7 & 46.2 & 49.6 & 49.68 \\
\hline & Room 4 & 58.2 & 45.9 & 56.4 & 45.5 & 51.7 & 51.54 \\
\hline & Room 5 & 53.7 & 48.9 & 42.2 & 47.1 & 48.4 & 48.06 \\
\hline & Room Avg & 54.6 & 50.92 & 47.98 & 47.88 & 51.06 & 50.488 \\
\hline
\end{tabular}


Table 5: Sample of the measurements (Blinds Down, Lights Off)

\begin{tabular}{|l|l|r|r|r|r|r|r|r|}
\hline & & \multicolumn{7}{|c|}{ Blinds Down, Lights Off } \\
\hline School 1 & & Foom 1 & 0.9 & 0.4 & 0.3 & 0.2 & 0.2 & 0.4 \\
\hline & Room 2 & 0.8 & 0.3 & 0.2 & 0.4 & 0.2 & 0.38 \\
\hline & Room 3 & 0.1 & 0.1 & 0.1 & 0.2 & 0.2 & 0.14 \\
\hline & Room 4 & 0.2 & 0.2 & 0.1 & 0.2 & 0.1 & 0.16 \\
\hline & Room 5 & 0.2 & 0.2 & 0.1 & 0.1 & 0.1 & 0.14 \\
\hline & Room Avg & 0.44 & 0.24 & 0.16 & 0.22 & 0.16 & 0.244 \\
\hline School 2 & Room 1 & 0.5 & 0.4 & 0.3 & 0.3 & 2 & 0.7 \\
\hline & Room 2 & 0.3 & 0.3 & 1.1 & 0.2 & 0.3 & 0.44 \\
\hline & Room 3 & 1 & 0.8 & 0.6 & 0.7 & 0.5 & 0.72 \\
\hline & Room 4 & 1.2 & 1.3 & 2.1 & 2.3 & 8.2 & 3.02 \\
\hline & Room 5 & 2.8 & 4.3 & 0.4 & 0.2 & 0.2 & 1.58 \\
\hline & Room Avg & 1.16 & 1.42 & 0.9 & 0.74 & 2.24 & 1.292 \\
\hline School 3 3 Room 1 & 0.2 & 0.2 & 0.6 & 0.4 & 0.2 & 0.32 \\
\hline & Room 2 & 0.5 & 0.9 & 0.4 & 0.6 & 0.6 & 0.6 \\
\hline & Room 3 & 1 & 2.1 & 1 & 2 & 1.9 & 1.6 \\
\hline & Room 4 & 0.8 & 0.3 & 0.8 & 0.6 & 0.7 & 0.64 \\
\hline & Room 5 & 0.4 & 0.4 & 0.4 & 0.3 & 0.2 & 0.34 \\
\hline & Room Avg & 0.58 & 0.78 & 0.64 & 0.78 & 0.72 & 0.7 \\
\hline
\end{tabular}

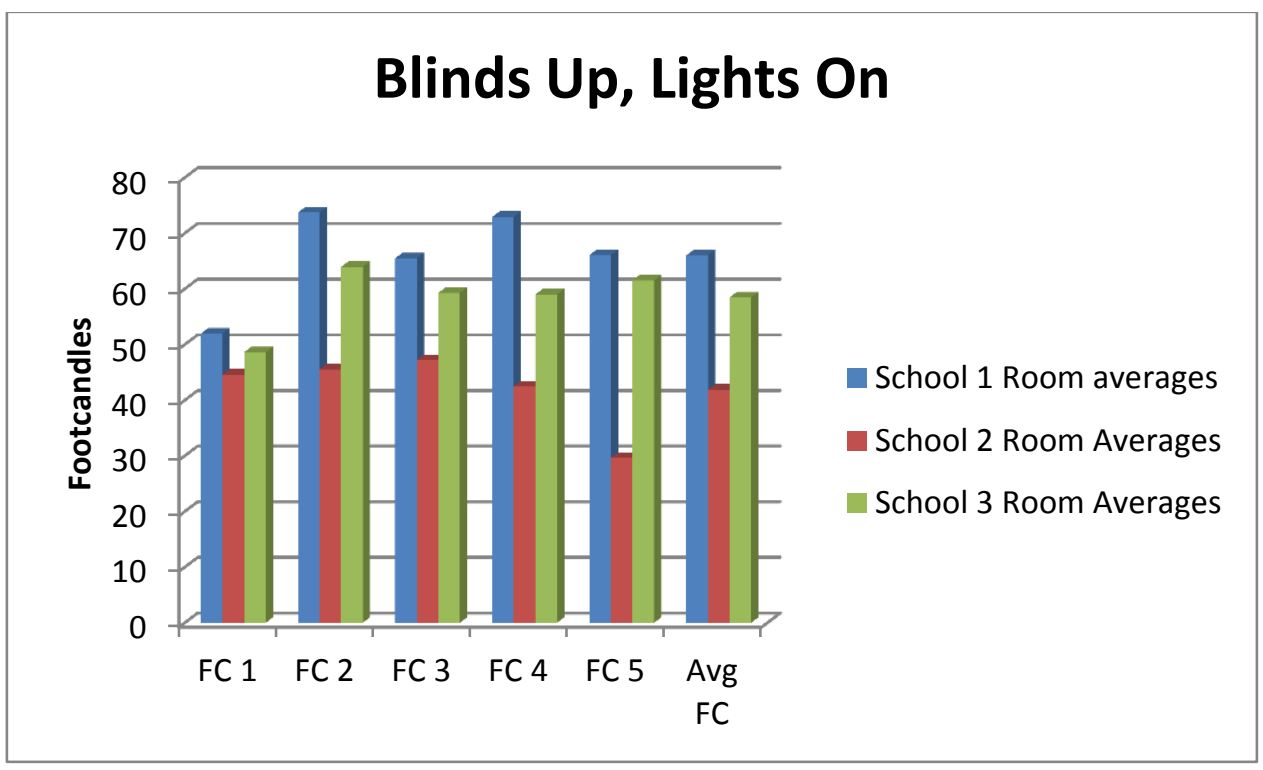

Figure 1: Illuminance (fc) comparison between schools (Blinds Up, Lights On) 


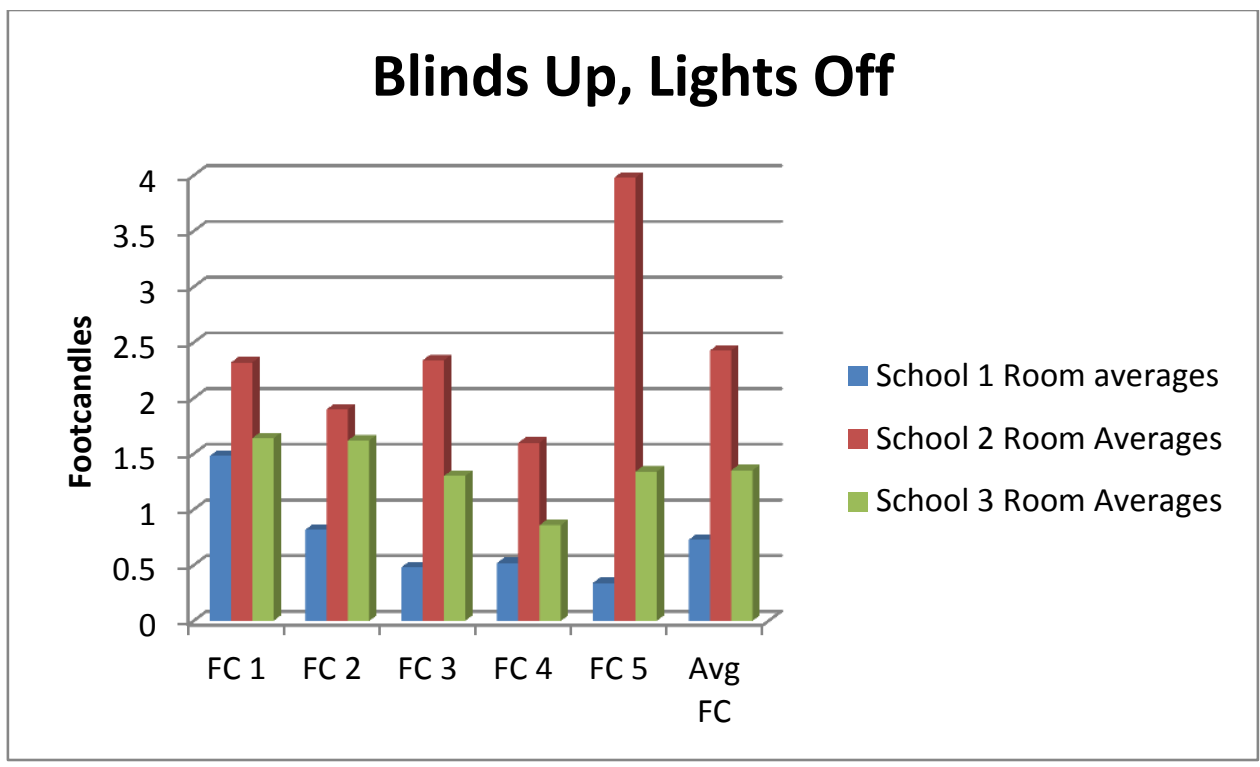

Figure 2: Illuminance (fc) comparison between schools (Blinds Up, Lights Off)

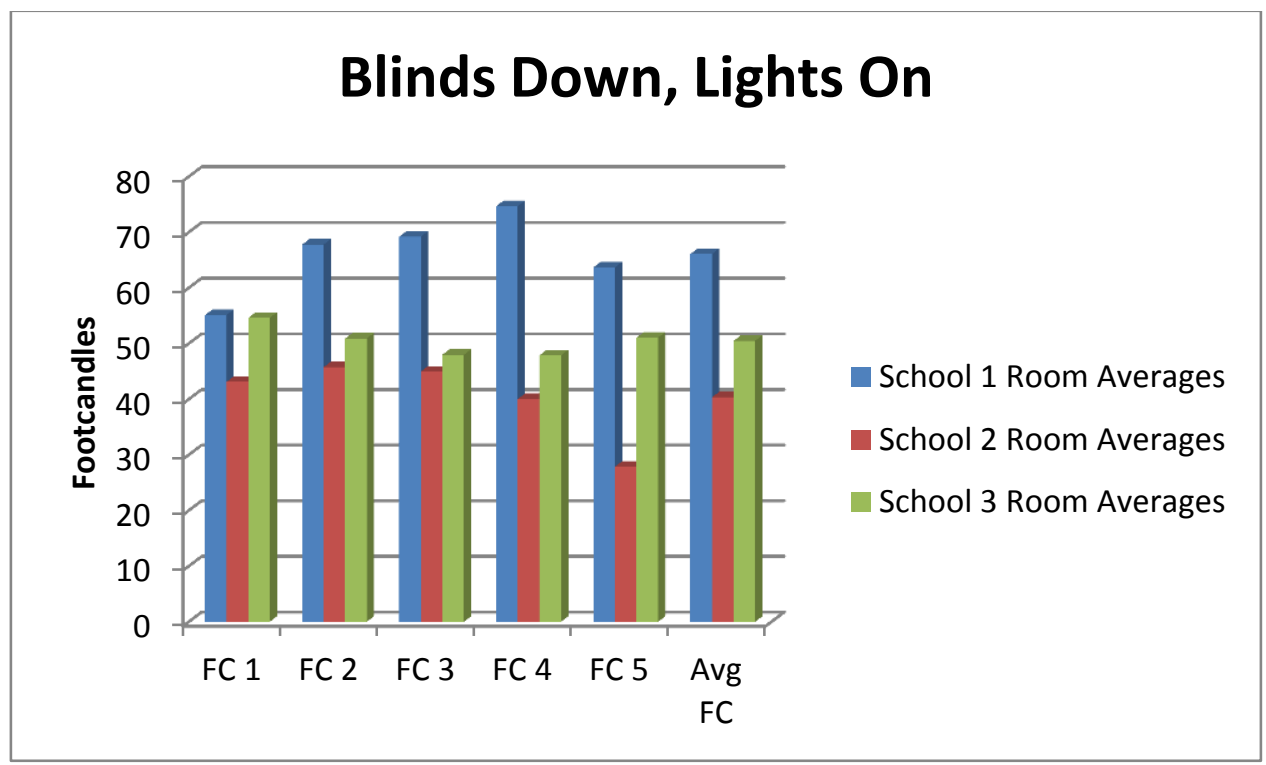

Figure 3: Illuminance (fc) comparison between schools (Blinds Down, Lights On)

Data Analysis: the averages of the illuminance measured in the classrooms are compared to the IES average that was decided in the hypothesis of $62 \mathrm{fc}$. Afterwards, the percent difference formula was used to calculate the differences in the room and school averages to our IES average. We need to point out that even though a room might appear to be failing the IES standards, any average in the percentage difference formula can drop to $-13 \%$ and still comply with the actual IES standards. 


$$
\text { Percent Difference }=\frac{F c_{\cdot \text { Avg. }}-I E S_{\text {Avg. }}}{\left(F c_{\cdot_{\text {Avg. }}}+I E S_{\text {Avg. }}\right) / 2} * 100
$$

Note: the absolute values of the percent difference formula was intentionally omitted to show either the excess or lack of light to the work plane.

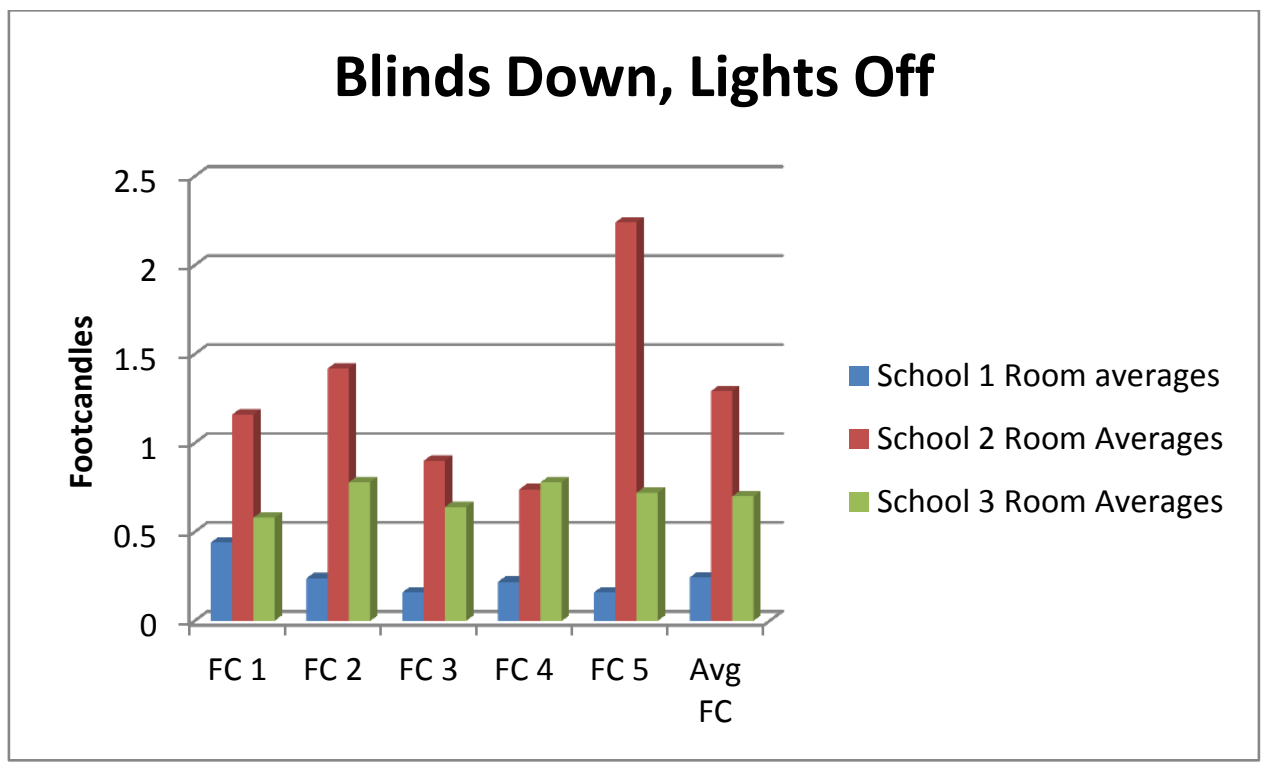

Figure 4: Illuminance (fc) comparison between schools (Blinds Down, Lights Off)

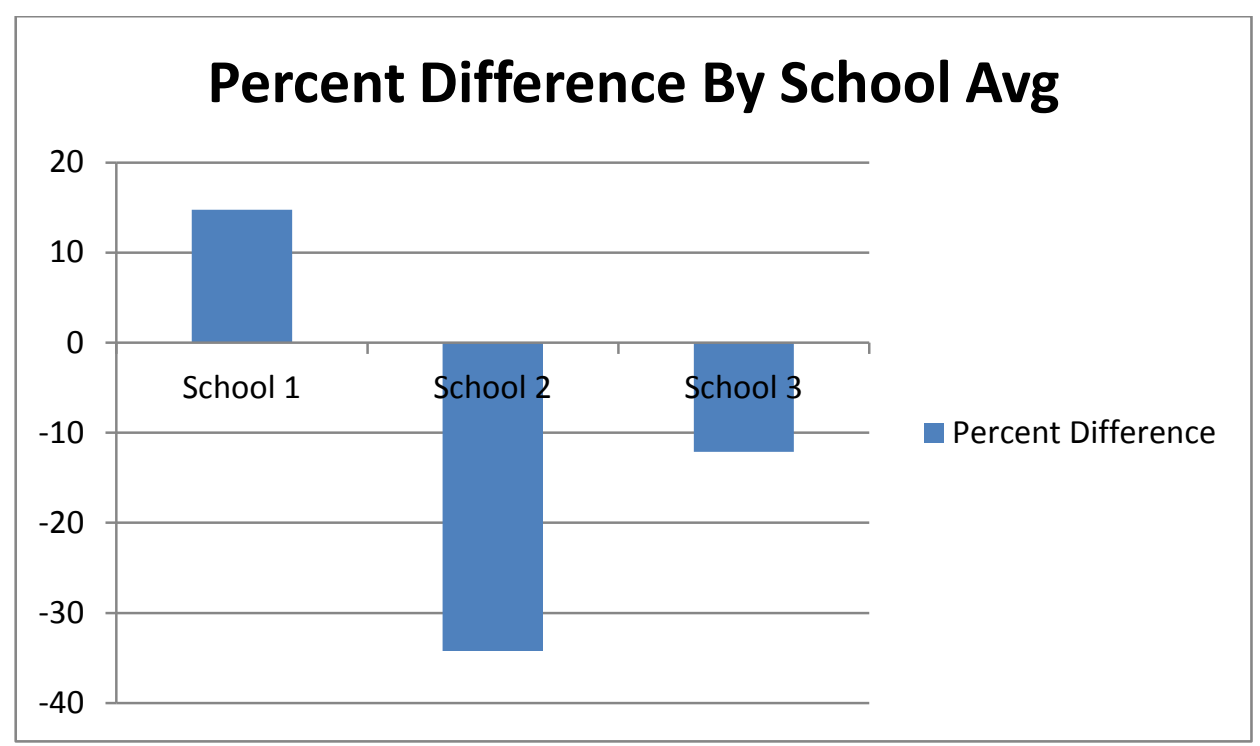

Figure 5: Percent Difference by school average illuminance

\section{Discussion:}

Within this project alone, there were a lot of variances that could be minimized, but not completely removed from the data. For example, the time of day, daylight and the weather conditions, and the 
amount of light transmitted through the windows are all variable that can only be controlled to some degree during the project. Options to minimize the false readings of the light reflected is to take the footcandle reading for the lights off and blinds up, and subtract it from the reading from the lights on and the blinds up. With this, the light reflected by the windows can be somewhat removed and not considered as a contributing factor in the lighting.

Another variance in the project is the amount of lamps that were burn out during the data collection process. In every classroom, there were at least two burns out lamps that could have easily lowered the amount of foot-candles that reached the work plane. If those lamps were operational, the readings for some of the lower foot-candle classrooms would have risen by at least $2 \mathrm{fc}$ and probably more depending on the amount of lamps were replaced.

Yet another variance in this project, is the amount of posters, cupboards, doors, etc. that cover a moderate percentage of the wall. Depending on the material and color of the items on the wall, the amount of reflected light reaching the work plane is severely reduced because of the amount of light absorbed by the items on the wall.

In conclusion, three elementary schools were measured to find the amount of light reached the work plane when compared to the recommended IES standards. Out of these three schools, schools one and three met the actual IES standards given, while only school one met the IES average that was assumed for elementary schools.

\section{Survey and Course Evaluation:}

The authors believe that the two subcategories of problem solving: Design and troubleshooting are misunderstood by the students and it is very important that the design course instructors need to be contacted and their voice be heard with regard to incorporating the topic of troubleshooting in teaching and learning Design. At the first level, a survey instrument that addresses two aspects of teaching engineering Design: the importance of the two subcategories, and the importance of the incorporation of these two subcategories in teaching engineering Design. We conduct this survey before and after the course during two consecutive years and the results are very similar.

The survey questions are:

Question 1: Do you understand the importance of "Design" for engineering education? (Not at all Important, Very Unimportant, Neither Important or Unimportant, Very Important, Extremely Important)

Question 2: Do you understand the importance of "Troubleshooting" in engineering education? (Not at all Important, Very Unimportant, Neither Important or Unimportant, Very Important, Extremely Important)

Question 3: Do you understand the difference between design and troubleshooting? (Much Lower, Lower, Average, Higher, and Much Higher)

Question 4: Do you think it is important to incorporate the topic of "troubleshooting" in Design Courses? (Not at all Important, Very Unimportant, Neither Important or Unimportant, Very Important, Extremely Important) 


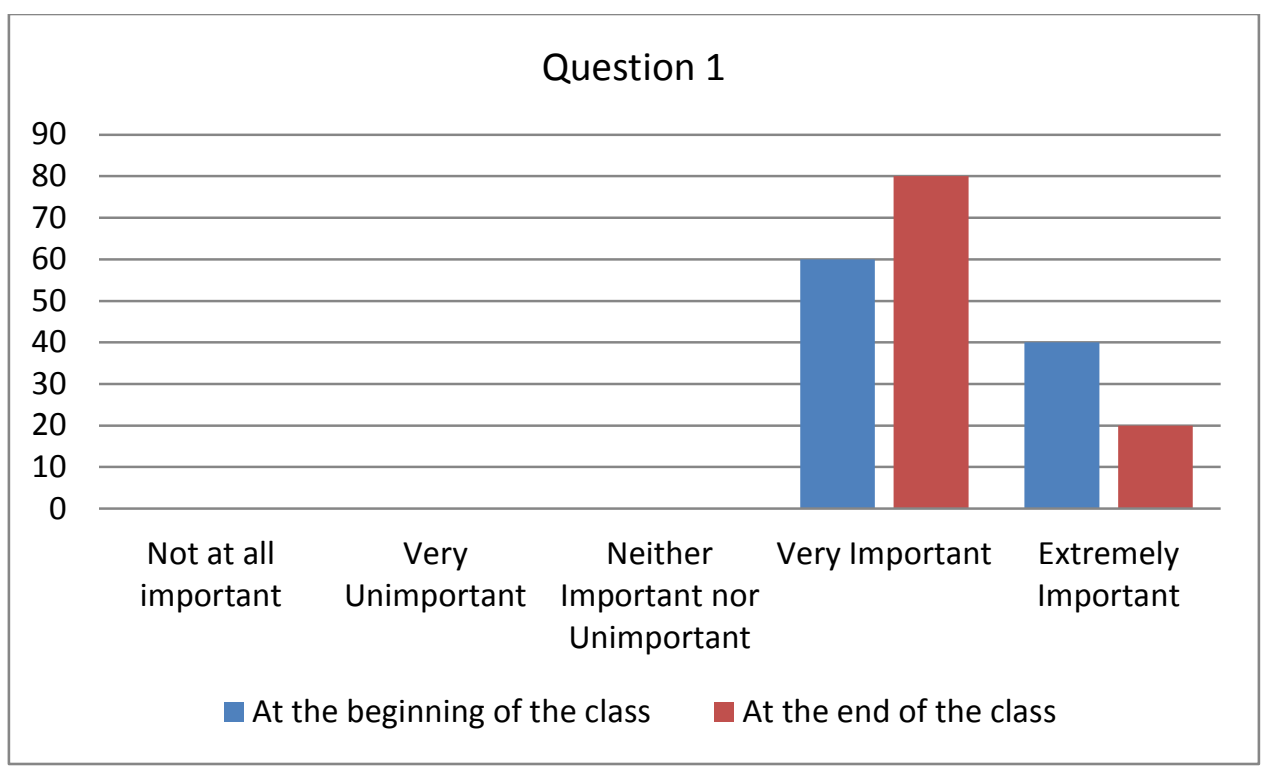

Figure 6: Question 1: Do you understand the importance of "Design" for engineering education?

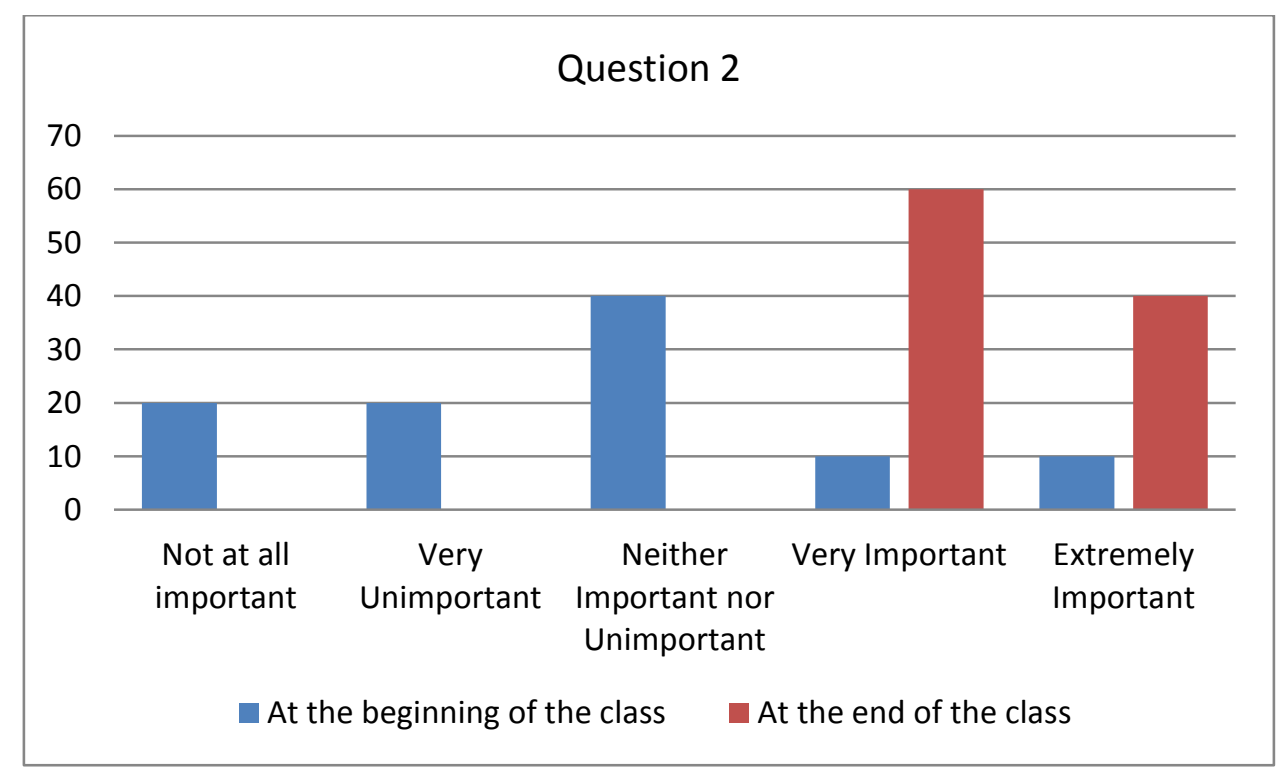

Figure 7: Do you understand the importance of "Troubleshooting" in engineering education?

Here, responses of design students to Questions 1, 2, and 3 are summarized. Based on the responses to Question 1, where the importance of design is similarly recognized at the beginning and the end of the semester, the respondents change their mind, regarding the importance of the teaching of troubleshooting within design courses. Regarding the Question 3 survey, we notice a progress in term of understanding of the difference between two aspects of problem solving: design and troubleshooting. 


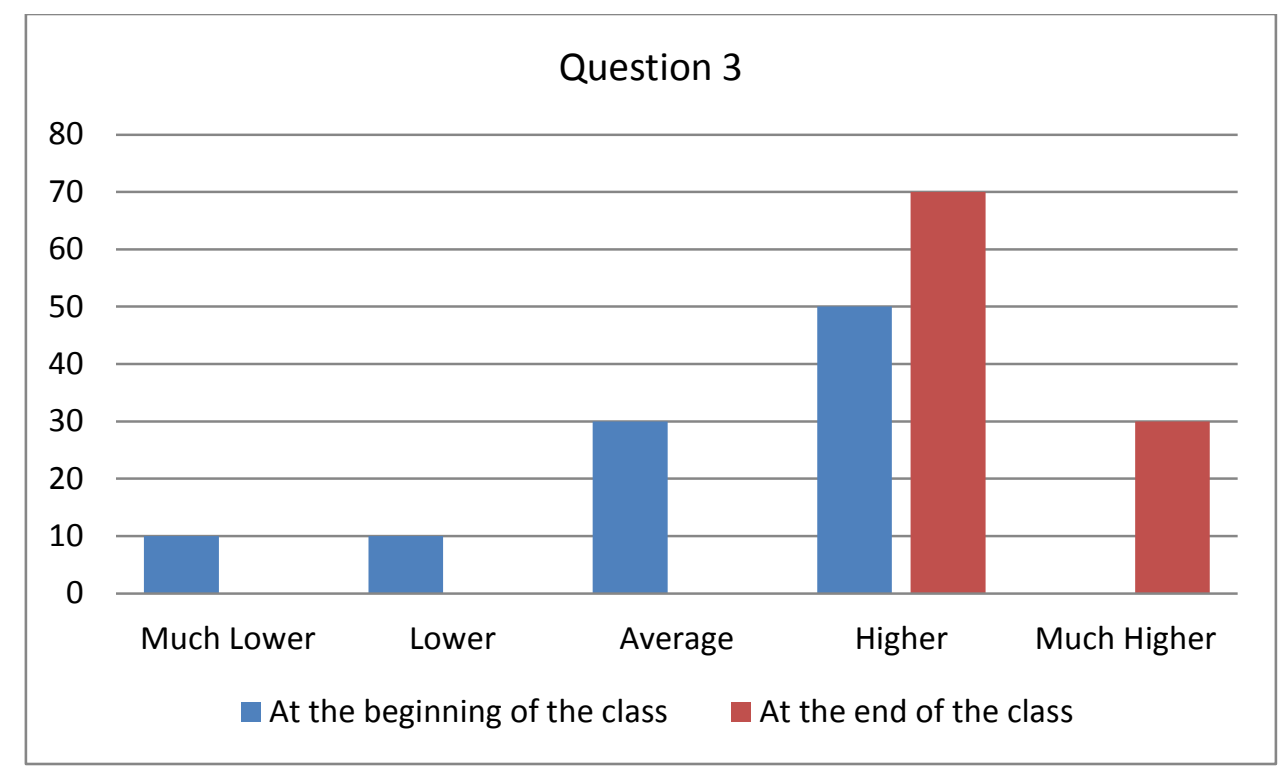

Figure 8: Do you understand the difference between design and troubleshooting?

\section{Indirect Assessment Results}

Using the indirect course evaluation form, students were asked, anonymously, to self-assess their ability in specific areas identified by the instructor in connection with the course learning objectives related to ABET. The compilation of the results of the student self-assessment of course learning objectives questions for AREN 348 are presented in Table 6. The student responses of "A" through "E" were converted to a 4.0 GPA scale in the standard way, with an "E" being considered equivalent to an " $F$ ". In this way, an equivalent class GPA was obtained for each question. The results of the students' assessment show that for all the questions, students generally feel like they are able to perform the task requested. The next step is to check if the assignments performed by the students will show the same positive answers.

\section{Direct Assessment Results}

The five course learning objectives were measured using exam questions and home works. The average grading of such exams and home works are shown in Table 7. One or multiple exam questions were associated with each learning objective, permitting that learning objective to be measured by direct assessment. The points scored per question were converted to a percentage scale and then to an "A" through "F" scale, using the traditional grade assignments. Table 7 shows the breakdown of letter grades received for each exam question. The equivalent class GPA is shown for each question, based on a 4.0 scale.

Direct assessment provides the most accurate measure of a student's knowledge in a given course. In this course, about $50 \%$ of students were able to have a grade of "A". The other $50 \%$ are subdivided between "B" and "C". Some students were not able to answer the questions successfully, obtaining grades of "F".

The direct assessment of the five learning objectives is relatively acceptable, but need improvement. 
Table 6: Results of Indirect Assessment for AREN 348 (fifteen students in the course)

\begin{tabular}{|l|l|l|l|l|l|l|}
\hline \multicolumn{2}{|c|}{ Indirect Assessment } \\
\hline $\begin{array}{l}\text { Student Self-Assessment of } \\
\text { Course Learning Objectives }\end{array}$ & $\begin{array}{l}\text { Number } \\
\text { of A's }\end{array}$ & $\begin{array}{l}\text { Number } \\
\text { of B's }\end{array}$ & $\begin{array}{l}\text { Number } \\
\text { of C's }\end{array}$ & $\begin{array}{l}\text { Number } \\
\text { of D's }\end{array}$ & $\begin{array}{l}\text { Number } \\
\text { of E's }\end{array}$ & $\begin{array}{l}\text { Equivalent } \\
\text { GPA (4 to 0 } \\
\text { scale) }\end{array}$ \\
\hline $\begin{array}{l}\text { Capable of understanding the } \\
\text { difference between } \\
\text { fundamentals: illuminance, } \\
\text { luminance, luminous flux, } \\
\text { and so on. }\end{array}$ & 10 & 3 & 2 & 0 & 0 & 3.53 \\
\hline $\begin{array}{l}\text { Capable of using point by } \\
\text { point method correctly }\end{array}$ & 12 & 2 & 1 & 0 & 0 & 3.73 \\
\hline $\begin{array}{l}\text { Capable of using Lumen } \\
\text { Method correctly }\end{array}$ & 12 & 2 & 1 & 0 & 0 & 3.73 \\
\hline $\begin{array}{l}\text { Capable of performing } \\
\text { building assessment: lighting } \\
\text { measurement }\end{array}$ & 10 & 5 & 0 & 0 & 0 & 3.66 \\
\hline
\end{tabular}

Table 7. Results of Direct Assessment for AREN 348 (fifteen students in the course)

\begin{tabular}{|l|l|l|l|l|l|l|}
\hline \multicolumn{2}{|c|}{ Direct Assessment } \\
\hline Course Learning Objectives & $\begin{array}{l}\text { Number } \\
\text { of A's } \\
\text { of B's }\end{array}$ & $\begin{array}{l}\text { Number } \\
\text { of C's } \\
\text { of D's }\end{array}$ & $\begin{array}{l}\text { Number } \\
\text { of E's }\end{array}$ & $\begin{array}{l}\text { Equivalent } \\
\text { GPA (4 to 0 } \\
\text { scale) }\end{array}$ \\
\hline $\begin{array}{l}\text { Capable of understanding the } \\
\text { difference between } \\
\text { fundamentals: illuminance, } \\
\text { luminance, luminous flux, } \\
\text { and so on. }\end{array}$ & 8 & 2 & 3 & 2 & 0 & 3.07 \\
\hline $\begin{array}{l}\text { Capable of using point by } \\
\text { point method correctly }\end{array}$ & 8 & 2 & 3 & 2 & 0 & 3.07 \\
\hline $\begin{array}{l}\text { Capable of using Lumen } \\
\text { Method correctly }\end{array}$ & 9 & 1 & 3 & 2 & 0 & 3.13 \\
\hline $\begin{array}{l}\text { Capable of performing } \\
\text { building assessment: lighting } \\
\text { measurement }\end{array}$ & 9 & 3 & 3 & 0 & 0 & 3.40 \\
\hline
\end{tabular}

In parallel with the self-evaluation of each course by the instructor, we also conducted a course evaluation by students. The course objectives introduced earlier in the course are again provided to the students at the end of the semester. The students' input on whether the materials offered have met the objectives is then complied and used in the program outcome assessment process. Results of instructor course evaluations (conducted by students) are reviewed by the department chair and the dean and shared with the faculty.

A more rigorous process in assessing the learning outcomes of this course will be implemented, which are in parallel with the program outcomes. The following outlines process will be used for this course assessment. 
- Individual instructor evaluation of the degree of learning achievement of individual students on a team, which includes consideration of the collective achievements of the team.

- Peer evaluation (optional by instructor).

- Grading of deliverables by the instructors (project plan, mid-term review, final report, exhibit (and abstract), oral presentation, team minutes, web site if applicable).

- $\quad$ Teamwork survey.

- Self-assessmen.t

- Senior Design Symposium judging (with evaluation criteria explicitly indexed to the learning objectives and articulated via rubrics for all measures).

\section{Conclusions:}

Teaching design courses for undergraduate students usually focus on design aspects of the concerned area, such as sizing different component of the main system, and system selection to be economic, safe, and in respects of the applicable codes.

The diagnostic aspects are usually ignored, since challenging and require real applications, where students need to perform experimental, auditing and even commissioning, as well as simulation works to analyze the system under consideration. These aspects are essential to promote student learning.

Both approaches are developed and tested through a case study. The case study concerned in this paper is the building illumination, and other issues encountered in modern residential and commercial buildings. The objective of this paper is to make a clear description familiarize them with the two approaches that usually will confront in their future.

Direct and indirect Assessment results, in connection with the course learning objectives, demonstrate the importance of the methodology developed. A more rigorous process in assessing the learning outcomes of this course will be implemented, which are in parallel with the program outcomes.

\section{References:}

ASHRAE. 1992 ASHRAE Standard 55-1992, Thermal environment conditions for human occupancy. Atlanta: American Society of Heating, Refrigerating and Air-Conditioning Engineers, Inc.

ASHRAE Standard 62-1999, «Ventilation for Acceptable Indoor Air Quality », American Society of Heating, Refrigerating and Air-Conditioning Engineers, Inc.

EPA, 1991, Indoor Air Facts No. 4 (revised) Sick Building Syndrome.

10th Edition of IES Lighting Handbook Editors David DiLaura, Kevin Houser, Richard Mistrick, Gary Steffy.

V. R. Benjamins, 'Problem-solving methods for diagnosis and their role in knowledge acquisition', International Journal of Expert Systems: Research and Applications, 8(2), 93-120, (1995).

Nickols, Fred (1994), "Reengineering the Problem Solving Process," Performance Improvement Quarterly, Vol. 7, No. 4. 
A. Stojcevski, R. Veljanovski, J. Singh, "Innovative Approach to University - Industry Partnership in Project Management", IADAT Journal of Advanced Technology, (2005).

Joseph McCade "Problem Solving: Much More Than Just Design"

Ritz, J. M., Deal, W. F., Hadley, F., Jacobs, J. A., Kildruff, T. F., \& Skena, K. G. (1986a). Problemsolving. The Technology Teacher, 46(2), 15-22.

Baker, G. E., \& Dugger, J. C. (1986). Helping students develop problem solving skills. The Technology Teacher, 45(4), 10-13.

P. Qvist, "Defining the Problem in Problem Based Learning", The Aalborg PBL Mode - Progress, Diversity and Challenges. Aalborg University press, (2004).

W. A. Nelson, "Problem Solving Through Design" in D.S. Knowlton and D.C. Sharp, eds., Problem Based Learning in the Information Age, New Directions for Teaching and learning, No 95, San Francisco: Jossey Bass, pp 39-44, (2003).

D. H. Jonassen, "Learning to Solve Problems: An Instructional Design Guide", John Wiley \& Sons, San Francisco, (2004). 